Психология. Журнал Высшей школы экономики.

2011. T. 8, № 1. С. $62-77$.

\title{
МЕТОДОЛОГИЧЕСКИЕ И КОНЦЕПТУАЛЬНЫЕ ПРОТИВОРЕЧИЯ НА СТЫКЕ ПСИХОЛОГИИ И ФИЗИОЛОГИИ
}

\author{
Б.В. ЧЕРНЫШЕВ, Е.Г. ЧЕРНЫШЕВА
}
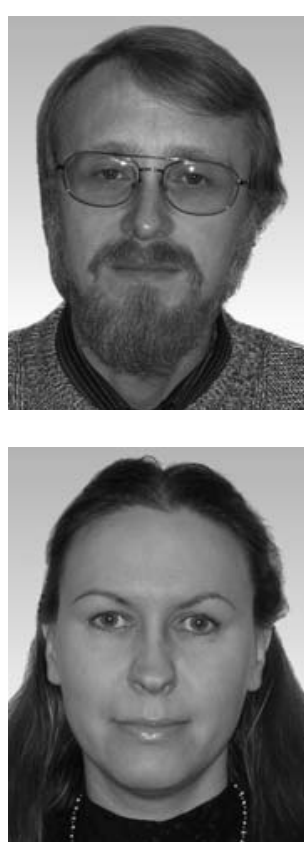

Чернышев Борис Владимирович - доцент кафедры психофизиологии факультета психологии НИУ ВШЭ, заведующий лабораторией когнитивной психофизиологии НИУ ВШЭ, доцент кафедры высшей нервной деятельности биологического факультета МГУ им. М.В. Ломоносова, кандидат биологических наук.

Контакты: bchernyshev@hse.ru
Чернышева Елена Георгиевна - заведующая лабораторией энцефалографии и полиграфических методов диагностики, старший преподаватель кафедры психофизиологии факультета психологии НИУ ВШЭ, кандидат биологических наук.

Контакты: echernysheva@hse.ru

\section{Резюме}

Статья посвящена рассмотрению актуальных вопросов, возникающих в результате интенсивного развития наук на стыке психологии и физиологии: психофизиологии, физиологии высшей нервной деятельности, нейропсихологии и др. В историческом контексте обсуждаются условия, определившие взаимодействие психологии и физиологии, противоречия методологического и концептуального характера, возникающие в области пересечения двух областей знания, а также границы и перспективы взаимного проникновения наук. Подробно рассматриваются две характерные исторически сложившиеся «болевые точки» взаимодействия наук - рефлекторная теория и нейрофизиологчческий (в том числе нейронный) анализ сознания.

Ключевые слова: психология, физиология, методология психологии, рефлекторная теория, сознание, нейроны сознания, психофизиологическая проблема. 
Психология занимается изучением души человека, а физиология (точнее, такая важнейшая ее область, как нейрофизиология) - изучением мозга. И если исторически эти науки сформировались совершенно независимо друг от друга, то вот уже более полутораста лет как намечается тенденция к их взаимопроникновению, что неизбежно ведет к спорам, противоречиям и путанице во многих вопросах. Отношение представителей одной науки к другой может колебаться от безоговорочного доверия и слепого заимствования до категорического непринятия. Нарастающая тяга наук друг к другу привела к тому, что внутри каждой из них образовалась область, далеко заходящая на территорию другой: со стороны психологии это психофизиология (или, говоря шире, физиологическая психология, включающая также и нейропсихологию), а со стороны физиологии - это физиология высшей нервной деятельности (которая по кругу вопросов приблизительно соответствует тому, что за рубежом называют психобиологией, биологической психологией или поведенческой нейронаукой). Более того, в настоящий момент на научном поле формируется такое новое многообещающее явление, как когнитивная наука, которая, вбирая в себя психологию, физиологию, филологию и философию, претендует на статус самостоятельной фундаментальной области знания.

Попробуем рассмотреть подробнее, допустим ли союз психологии и физиологии. Могут ли физиологи использовать терминологию психологов, созданные ими понятия и методики? Могут ли психологи обра- щаться к достижениям физиологической науки и, главное, доверять им? Можно ли вообще, изучая мозг, изучать одновременно и психику, или же эти занятия совершенно несовместны друг с другом? История развития двух наук с очевидностью показывает, что проблема действительно существует, а непосредственным толчком к написанию данной работы явились публикация В.П. Зинченко «Ответ психолога физиологам» (Зинченко, 2009) и плодотворные дискуссии с ее автором.

Проблема, вынесенная в заголовок статьи, представляется чрезвычайно важной в методологическом плане, поскольку вопрос методологии в рамках психологической науки стоит достаточно остро (Василюк, 2003; Мазилов, 2006), а концептуальное и методологическое взаимопроникновение психологии и (нейро)физиологии еще более осложняет ситуацию. Тесное родство современной науки о мозге и современной психологии может создать иллюзию, что эти науки уже объединились, однако это совсем не так, и на самом деле методологический и понятийные барьеры между ними все еще высоки.

Корень разногласий между двумя науками в значительной степени связан с нерешенностью так называемой психофизиологической проблемы («mind-body problem»). По современному состоянию науки эту проблему можно сформулировать как вопрос о соотношении ментальных состояний (чувств, желаний, мыслей и т.п.) и физических состояний мозга. С грустью можно констатировать, что сейчас мы почти столь же далеки от ее решения, как и несколько столетий назад. 
Однако сама по себе эта проблема слишком глобальна и относится скорее к области философии, чем собственно психологии или физиологии. Нерешаемость данной проблемы лишает смысла разговор о ней в рамках как физиологии, так и психологии, и поэтому далее мы остановимся лишь на двух характерных болевых точках на стыке психологии и физиологии. Мы рассмотрим сначала достаточно старую идею, согласно которой психика строится из набора рефлексов, а затем более позднюю, но тоже очень распространенную мысль, согласно которой в активности отдельной нервной клетки можно увидеть психику человека. В обоих случаях психологов отпугивает редукционизм, характерный для физиологии, превращение сложнейшего явления психики в фактор одного нехитрого эксперимента. Но существует ли эта проблема на самом деле, или же это своего рода «трудности перевода» между языком психологии и языком физиологии и обратно?

$$
* * *
$$

Изначально, когда о сложной работе мозга еще ничего не было известно, вопрос ставился довольно просто: каковые причины, заставляющие живое существо выполнить то или иное движение? Что заставляет сокращаться мышцы нашей руки, если мы случайно дотронемся до горячего предмета? А что заставляет художника взять кисть, обмакнуть ее в краску и начать водить ею по холсту? Можно ведь построить машину, которая в принципе будет делать то же самое. В эпоху расцвета механики действительно были созданы человекоподобные машины, которые могли даже написать письмо или сыграть на флейте - впрочем, ни на что больше они не были годны и оставались лишь изысканными игрушками.

Итак, идея рефлекса - равно как и зерна самой психофизиологической проблемы в ее современном понимании - возникла в трудах выдающегося мыслителя XVII в. Рене Декарта. Ведь именно начиная с его основополагающих трудов и до относительно недавнего времени в науке - а именно в оформившихся значительно позднее физиологии и психологии - было принято считать, что живое движение осуществляется по рефлекторному принципу, т.е. каждая двигательная реакция является ответом на какой-либо сенсорный стимул (Декарт, 1994). Связующим звеном между сенсорным стимулом и мышечным движением, согласно Р. Декарту, является работа нервной системы. Конечно же, представления передовых мыслителей XVII в. о механизмах функционирования нервной системы были чрезвычайно наивными, но мы не будем акцентировать на этом внимание: ведь базовая идея Р. Декарта о двунаправленной передаче сигнала от органов чувств к мозгу и затем от мозга к мышцам вполне ясна и не противоречит современным представлениям.

Следует сказать, что с помощью такой схемы (названной впоследствии рефлекторной) Р. Декарт предлагал описывать лишь простейшие движения, подобные отдергиванию ноги от обжигающего огня. Он полагал, что более сложная человеческая 
деятельность обеспечивается душой, которая способна управлять телом через посредство шишковидной железы (эпифиза) в мозге. Таким образом, психофизиологический дуализм представлений Р. Декарта состоял в том, что, по его мнению, движения разного уровня имеют принципиально различные причины. И есть два таких уровня, один из которых полностью лежит в сфере материального, т.е. по его терминологии «протяженного», а другой - нет. Человек представляет собой сочетание протяженного тела и мыслящего духа. Связь между ними, конечно, должна существовать (иначе как «непротяженная» мысль приводит к движению вполне «протяженных» частей тела?), но как она устроена - не понятно. Возможно, именно так был заложен будущий раскол между психологией и физиологией, граница между двумя науками. Важно отметить, что, согласно Р. Декарту, нематериальная мыслящая субстанция (res cogitans) доступна нам непосредственно путем самонаблюдения, и ее существование - единственное, в чем мы не должны сомневаться (cogito, ergo sum). По его мнению, в отличие от мира духовного, мир материальный может оказаться иллюзией, навязанной дьяволом или какой-либо иной могущественной силой. Здесь попутно нельзя не вспомнить известный фильм «Матрица» (Warner Bros. Entertainment Inc., 1999, режиссеры - Э. Вачовски и Л. Вачовски): герои фильма усомнились в реальности материального мира, который, как оказалось, действительно был иллюзией, навязанной им коварными машинами; но, обратите внимание, реальность своего собственного сознания, своей личности не подвергалась ими сомнению.

Заметим, что идея привязки «непротяженной», т.е. идеальной субстанции - души к «протяженному» телу через одно конкретное место в мозге - шишковидную железу, - вероятно, выглядела не очень убедительной даже в XVII в. Видимо, сам Р. Декарт выбрал именно шишковидную железу потому, что, во-первых, согласно представлениям того времени, она, как и душа, неделима на части (в том числе, в отличие от всего мозга, она не разделяется на левую и правую половину); во-вторых, она располагается в центре мозга близко к желудочкам. Это казалось тогда очень важным, так как, согласно представлениям того времени, работа мозга связывалась именно с желудочками, а не с мозговой тканью как таковой. Впоследствии Р. Декарт стал отказываться от идеи связи между душой и телом через шишковидную железу, поскольку никак не мог объяснить этой связи; и это было самое слабое место его теории. Кстати, не следует забывать, что Р. Декарт подвергался серьезным гонениям со стороны церкви, и не исключено, что в своих сочинениях он был вынужден искажать и маскировать свои идеи, что может затруднять понимание истинного хода его мыслей.

Вообще говоря, идея об осуществлении связи между духовным и телесным через посредство шишковидной железы возникала впоследствии еще неоднократно; например, в свете одного реального анатомического открытия конца XIX в. шишковидную железу в оккультизме стали отождествлять с мистическим «третьим 
глазом». Современному образованному человеку подобные мысли должны казаться как минимум странными, в особенности привязка сознания человека, его человеческой сущности к одной маленькой области мозга. Этим, кстати, не преминул воспользоваться М.А. Булгаков в повести «Собачье сердце»: превращение собаки в весьма нелицеприятного человека произошло как результат эксперимента с пересадкой гипофиза от человека к собаке (не исключено, что М.А. Булгаков намеренно заменил эпифиз на гипофиз, так как пересадить гипофиз технически невозможно, а сторонники эзотерических учений начала XX в. путали эти структуры достаточно часто). Нужно признаться, что и сейчас, несмотря на огромную работу множества ученых, мы так и не имеем никакого определенного и вразумительного ответа на вопрос, как же душа (или психика?) связана с мозгом. Свидетельством тому является наличие множества разнообразных и нередко взаимоисключающих теорий по этому поводу.

$$
* * *
$$

В дальнейшем логика развития науки вплоть до XIX в. привела к тому, что для разрешения дуалистической позиции Р. Декарта сформировались как минимум два различных подхода.

Многие физиологи изучали лишь рефлекторную составляющую управления движениями и прочих физиологических реакций, полагая при этом, что движения, возникающие при участии головного мозга и имеющие психическую природу, выходят за рамки физиологической науки; такова, в частности, была логика работ выдающихся физиологов XIX в. Ч. Белла, Ф. Мажанди, М. Холла, придавших рефлекторной теории анатомическое основание. Сходной логике подчиняется значительное количество физиологических исследований, выполненных в XX в. и проводящихся до настоящего времени. Хотя данный подход позволяет успешно исследовать физиологические процессы, он ведет к полному отрыву физиологии от психологии и к неспособности физиологии изучать многие важнейшие аспекты человеческой деятельности. С другой стороны, этот подход полностью корректен, и именно его придерживались выдающиеся физиологи прошлого (включая Ч. Шеррингтона), благодаря деятельности которых рефлекторная теория и приобрела свое огромное значение. Необходимо заметить, что Ч. Шеррингтон, как и многие другие физиологи, прекрасно понимал сложность функционирования нервной системы и еще в 1906 г. в книге «Интегративная деятельность нервной системы» (Шеррингтон, 1969) подчеркивал, что благодаря взаимодействию сложнейшей системы рефлексов они приобретают целенаправленный характер; более того, согласно его мнению, рефлексы - лишь наиболее простые проявления сложных и интерактивных процессов в нервной системе, которая действует как единое целое. С другой стороны, Ч. Шеррингтон оставался упорным дуалистом почти в декартовском духе и считал, что психические явления выходят за рамки компетенции физиологии и должны изучаться в другой науке - 
психологии. И.П. Павлов также всячески подчеркивал необходимость разграничения физиологического и психологического подходов и нежелательность переноса понятий из психологии в физиологию (Павлов, 1951, 2010). А.А. Ухтомский, споривший с И.П. Павловым по многим вопросам, настаивал на разграничении физиологического подхода и изучения субъективного, подчеркивая при этом, что «субъективное» и «объективное» способны непосредственно переходить одно в другое (Ухтомский, 1978).

Психология, в свою очередь, в основном формировалась по другую сторону от водораздела психофизиологической проблемы. Психологи далеко не всегда в своих научных построениях учитывают физиологию мозга. Этот подход также оправдан, корректен и может успешно применяться в большинстве случаев. Действительно, пока человек здоров и не одурманен каким-либо наркотиком или токсином, вносить мозг в качестве еще одного неизвестного в психологические теории - значит плодить сущности сверх необходимого, что запрещено нам «бритвой» У. Оккама. И все верно до тех пор, пока не приходится сталкиваться с фактами удивительных видоизменений психики под действием фармакологических веществ, травм головы, гормональных изменений в организме, магнитной и электрической стимуляции мозга и других естественных и искусственных событий, затрагивающих телесную оболочку человека. Пожалуй, одно из самых ярких следствий воздействия на мозг это выявление двух независимых сознаний у больных с «расщепленным мозгом» (т.е. с перерезанным мозолистым телом) в работах Р. Сперри (Sperry, 1968).

$$
* * *
$$

Итак, можно было закрыть глаза на психофизиологическую проблему и отступить от нее как от непреодолимой преграды (благополучно пребывая при этом с одной или с противоположной еe стороны). Другой возможный путь на уровне знаний XIX в. состоял в том, чтобы декларировать, что все процессы в мозге, в том числе и составляющие суть человеческой психики, являются по своей сути рефлекторными. Ярким примером данного подхода является позиция выдающегося русского физиолога И.М. Сеченова (1829-1905), выраженная им в книге «Рефлексы головного мозга» (Cеченов, 1961). Эта книга увидела свет в 1863 г. и получила большой общественный резонанс. По-видимому, многие заявления, выраженные в этой книге и в других публикациях И.М. Сеченова, имели полемический характер в контексте того времени и были направлены, прежде всего, на обоснование физиологического подхода к психическим процессам (кстати, первым названием данной работы, запрещенным цензурой того времени, было «Попытка ввести физиологические основы в психические процессы»). Иными словами, речь шла, прежде всего, о доказательстве принципиальной связи между психикой и мозгом и теоретической возможности изучать все процессы в мозге с помощью физиологических методов, которые в силу методических ограничений на тот момент 
были, к несчастью, связаны лишь с идеей рефлекса.

Важнейшим элементом подхода, сформулированным И.М. Сеченовым, который, впрочем, был впоследствии подвергнут сомнению и отчасти опровергнут, является постулат о том, что причиной любого явления, происходящего в нервной системе, непременно является сенсорное возбуждение. Оценивая это утверждение, не следует забывать, что на уровне представлений, широко распространенных в то время и не исчезнувших до сих пор, основная альтернатива состоит в сверхъестественных способах получения сведений о мире непосредственно самой душой, минуя органы чувств. Так что на уровне науки того времени позиция И.М. Сеченова была, по сути, единственно правильной, а отстаивание подобных «материалистических» идей в условиях тогдашней России потребовало от него большого личного мужества.

В дальнейшем идея о рефлекторном характере всякой нервной деятельности закрепилась в науке в своем буквальном понимании и, в конечном счете, оказала огромное влияние на развитие, прежде всего, отечественной, но также и всей мировой физиологии и психологии. В частности, И.П. Павлов в 1932 г. в известной работе «Ответ физиолога психологам» (Павлов, 1951) настаивал на том, что любые психические процессы привязаны к своей материальной основе - мозгу (принцип структурности). И был по сути дела прав, если не считать, что в тот момент он еще не мог выйти за пределы собственной рефлекторной доктрины. Итак, к сожалению, принцип материальной привязки психических процессов к мозгу воспринимался в жесткой связке с рефлекторным принципом, поскольку на тот момент других развитых методологических доктрин у физиологии, помимо рефлекторной, просто еще не было.

Как известно, любую разумную точку зрения можно при желании довести до абсурда, если вырвать ее из контекста, усилить в ней что-то одно и отбросить важные детали. В нашей стране это, по сути дела, и случилось, и из точки зрения о потенциальном существовании физиологических основ психики было выведено утверждение о ненужности психологии как таковой, что не только больно ударило по отечественной психологии, но и посеяло стойкое недоверие к физиологии со стороны психологов.

Заметим, что уже в самом начале XX в. могло бы стать ясно, что рефлекторный принцип не всегда годится даже в пределах самой физиологии, причем дело вовсе не в пресловутом «материализме» рефлекторной теории. Так, в частности, согласно рефлекторной точке зрения даже сложные последовательности движений (например, движения конечностей при локомоции) представляют собой ассоциации рефлексов, в которых мышечное чувство от предыдущего движения становится пусковым стимулом для последующего. Такое заявление можно иногда, к сожалению, встреть даже в относительно современной учебной литературе. Но на самом деле последовательности движений - от врожденных (таких как 
локомоция) до приобретенных (подобных навыкам управления автомобилем или игры на музыкальном инструменте), - как правило, задаются некоторой относительно $а в$ тономной центральной программой, способной ограниченно функционировать даже в отсутствие сигналов обратной связи от сенсорных органов и нуждающейся в этих сигналах лишь для коррекции движения, но не для осуществления движения как такового. Например, сейчас хорошо известно, что в спинном мозге имеется автономный «генератор локомоции», который даже в отсутствие сенсорных входов задает последовательность мышечных сокращений, нужных для локомоции. Сама по себе эта идея возникла в физиологических работах Т.Г. Брауна еще в начале $\mathrm{XX}$ в., причем в его работах она получила строго экспериментальное обоснование (Brown, 1911), однако из-за преобладания в науке рефлекторных представлений Ч. Шеррингтона и И.П. Павлова она оставалась незамеченной и невостребованной на протяжении целого полувека. Ведь идея рефлекса была столь удобна и привычна!

Важнейшей вехой в развитии как физиологии, так и психологии явились работы выдающегося отечественного физиолога Н.А. Бернштейна, посвятившего свою жизнь изучению принципов управления и биомеханики движений. Крайне важным для понимания важнейших основ управления движениями является выдвинутый Н.А. Бернштейном принцип активности (т.е. совершения двигательных актов на основе внутренней двигательной программы) в противопоставлении принципу реактивно- сти (т.е. рефлекторного выполнения движения непосредственно в ответ на стимул). Согласно этим представлениям, автоматическое выполнение движения в ответ на стимул является лишь частным случаем двигательной активности, в то время как в подавляющем большинстве случаев организм формирует собственную двигательную программу (Бернштейн, 1966, 1990). При этом все движения, которые имеются у животного или человека, можно расположить в ряд на некоторой воображаемой оси по степени их определяемости внешним стимулом. Тогда на одном полюсе окажутся безусловные рефлексы, запрограммированные морфологически. Практически на том же уровне следует расположить и классические условные рефлексы, подобные тем, которые наблюдал И.П. Павлов у собак. На противоположном полюсе этой оси окажутся произвольные движения.

Судьба Н.А. Бернштейна показывает нам, как рефлекторная теория, служившая мощным двигателем науки на протяжении нескольких столетий от Р. Декарта до Ч. Шеррингтона и И.П. Павлова, стала тормозить науку. Противостояние приобрело особенно трагические и застойные формы в нашей стране, однако во всем мире преодоление рефлекторной теории было непростым и мучительным процессом. Ведь рефлекторная теория в принципе верна, как верна механика И. Ньютона; но она должна занять подобающее ей место частного случая в свете современного понимания механизмов работы мозга, подобно тому как механика И. Ньютона стала частным случаем теории относительности. 
И потому все споры о нужности и истинности рефлекторной теории лишены смысла; она нужна и истинна, но ее нельзя применять ко всем случаям подряд, так как с того времени произошел значительный скачок в понимании этого вопроса. Именно так и нужно относиться к рефлекторной теории (см.: Василюк, 2003).

Заметим, что, по нашему мнению, плохо не только быть ярым сторонником рефлекторной теории, но столь же плохо быть ее ярым противником. Некогда навязывание психологам рефлекторной теории вызвало мощное ее отторжение (что не удивительно, ведь она действительно не подходит для объяснения высших психических функций человека). В результате многие психологи стали считать рефлекс чем-то ненужным. Сведение психики к речевому мышлению, представление о том, что все, что делает человек, он делает обдуманно и сознательно, столь же неверно, как и слепая вера во всемогущество рефлекторной теории.

Кстати, в уже рассмотренной нами выше попытке И.М. Сеченова и его последователей свести психику к рефлексу, как в капле воды, отразилась та грань между физиологией и психологией, поняв которую можно понять и суть противоречий и соперничества между этими науками. Нейрофизиология и психология изучают разные, хотя и соседние уровни устройства мироздания. Соответственно, каждая из них обладает своей методологией. Сможет ли ученый, изучивший каплю воды и не знающий ничего, кроме этого, опи- сать шторм на море? Нет, разумеется, не сможет. Но сможет ли другой ученый, желающий точно описать суть океанского шторма, сделать это, ничего не зная о капле воды и не видя ее? Дать общее поверхностное представление о шторме он сможет, но создать модель шторма, обладающую силой предсказания, - нет. Наверное, каждому из этих ученых будет полезно знать о работе другого, и тогда описание океана станет более точным и достоверным, а описание капли станет более осмысленным, более целостным, более сфокусированным. Нужно лишь, чтобы каждый из них помнил о пределах дозволенного в рамках его собственной методологии и не смотрел на каплю в подзорную трубу, а на океан - в микроскоп.

Аналогичное противоречие возникает, например, на границе между биологией и химией, также изучающими два смежных этажа мироздания. Ведь для биолога работа химика покажется безмерным упрощением, редукцией функций живого организма: химик стремится провести в своей пробирке одну-единственную химическую реакцию, а в живой клетке одновременно совершаются тысячи, если не миллионы, химических реакций, составляющих вместе совершенно новое качество - жизнь. Как показало развитие современной науки, синтез этих наук пошел на пользу им обеим.

\section{$* * *$}

Итак, психология и (нейро)физиология изучают смежные уровни организации одного и того же явления мысль, в общем, не оригинальная, но 
часто забываемая. А такая смежность предмета исследования должна неминуемо вести и к заимствованиям терминологии - весьма болезненному вопросу взаимоотношений между двумя наукам. Обмен терминами и понятиями между физиологией и психологией происходит достаточно интенсивно, но после заимствования эти термины и понятия меняются ради того, чтобы вписаться в исходно чуждую им методологию. $\mathrm{B} \mathrm{XX}$ в. произошло проникновение в физиологию ряда психологических понятий, в том числе таких основополагающих, как мотивация, внимание и даже сознание. Это было нужно физиологии, так как старые доктрины во многом изжили себя и ограничивали развитие науки (точнее, грозили ей однобокостью и практической бесплодностью). А далее стало происходить следующее. Методологический аппарат физиологии был в принципе пригоден для изучения этих явлений, но - и это важно - потребовал некоторого изменения понятий. Поскольку изменение значения терминов происходило плавно и незаметно, новый термин в рамках физиологической науки, как правило, не формировался. А в результате мы имеем характерную путаницу, вводящую многих в заблуждение. (Заметим попутно, что подобная путаница терминологии нередко встречается даже в пределах одной науки, если одним термином пользуются в нескольких разных научных школах.) Самым спорным, наверное, является, заимствование физиологией из психологии термина «сознание», к которому мы вернемся ниже.
$* * *$

Еще одна болевая точка контакта между психологией и физиологией связана с верой физиологов в то, что, поняв работу нейрона, мы поймем и психику человека. В 1950-1960-е гг. физиологам вскружили голову первые успехи регистрации электрической активности нейронов, в том числе выдающаяся серия работ С. Куффелера по изучению работы сетчатки глаза. Это был крупнейший методологический прорыв в нейрофизиологии, наверное, следующий за открытием электроэнцефалограммы Г. Бергером. Если открытие ЭЭГ дало начало зарождению психофизиологии в современном смысле, то открытие методов регистрации нейронной активности революционизировало всю нейрофизиологию в целом. Пожалуй, это был столь же грандиозный прорыв, открывший широчайшие перспективы перед нейрофизиологией, как изобретение микроскопа А. ван Левенгуком, преобразившее некогда биологию. Следует попутно заметить, что с того времени в нейрофизиологии произошел лишь еще один существенный методический скачок - изобретение томографических методов визуализации активности мозга (функциональной магнитно-резонансной томографии, позитронно-эмиссионной томографии и их разнообразных модификаций).

Нейрон стал мыслиться как основа психики почти в буквальном смысле. Фантасты в этом отношении чувствуют себя свободнее, чем ученые, и увлечение нейронами ярко проявилось в романе А. Азимова. 
Этот писатель в своем творчестве всегда был неравнодушен к вопросам, связанным с работой мозга и с таинственной гранью между физическими процессами в мозге и психикой. Но если в его ранних произведениях описаны выдуманные им роботы с «позитронным мозгом», живущие и действующие почти как люди, то в более поздних книгах автора (таких как «Фантастическое путешествие II: место назначения мозг») сюжет уже напрямую касается физиологии человеческого мозга. Герои упомянутой книги посчитали необходимым сесть в некий подводный аппарат наподобие батискафа и уменьшиться до молекулярных размеров - ради того, чтобы прочитать мысли человека. Для чтения мыслей им нужно было зарегистрировать некие «скептические волны мозга», причем автор вместе с героями убеждены, что для чтения мыслей достаточно уловить сигналы от одной-единственной клетки. Еще одна яркая подробность: наилучшего приема «скептических волн» герои намеревались добиться в синапсе нейрона. Надо отдать должное автору: прочитать мысли героям книги так и не удалось, хотя это произошло по не зависящим от них обстоятельствам.

Если оставить в стороне художественный вымысел и вернуться к науке, то вся вторая половина XX в. в той или иной степени прошла для нейрофизиологии как раз под флагом изучения одиночного нейрона. Всем хотелось верить, что, зарегистрировав нейрон в правильном эксперименте и применив правильный алгоритм расшифровки его сигналов, мы сможем заглянуть в психику.
Многие не потеряли эту надежду и сейчас.

Действительно, первые успехи, достигнутые в 1950-1960-е гг., были потрясающими. Так, уже упоминавшийся выше С. Куффлер раскрыл важнейшие принципы работы сетчатки. Вслед за ним Д. Хьюбел и Т. Визель поняли многое из того, как работает зрительная кора (пускай эти открытия сейчас отчасти ставятся под сомнения, но это нормально, наука всегда развивается через отрицание, а Нобелевская премия нашла своих лауреатов вполне заслуженно). Э. Эвартс сделал аналогичный прорыв в отношении двигательной коры. И теперь ни один учебник по физиологии ЦНС не обходится без описания этих и ряда подобных им работ, пришедшихся в основном на конец 1950-х - 1960-е гг., а картинки с кошкой, смотрящей на экран со световой полоской, и обезьяны, двигающей рычаг, стали традиционными для учебников и популярной литературы в этой области. Последовали и многие другие выдающие работы, заложившие основы современной нейрофизиологии.

Естественно, исследователи не хотели ограничиваться лишь первичными сенсорными и моторными областями коры больших полушарий, которые у человека составляют лишь очень незначительную долю от ее общей площади. Даже у обезьян огромная часть коры больших полушарий не имеет простой и очевидной связи с сенсорными и моторными функциями, легко поддающимися физиологическому описанию. И здесь стало труднее. Ведь недаром эти огромные «белые пятна» мозга получили в свое время название «ассоциативных» 
(вероятно, это неудачное название, но оно, тем не менее, прочно вошло в научный обиход; под «ассоциативностью» в данном случае понимается всего лишь наличие связей каждой такой области с несколькими первичными, создающих анатомичесжую почву для ассоциаций). Интерпретация результатов исследования ассоциативных областей коры и ряда подкорковых структур становилась просто невозможной в чисто физиологических терминах, и физиологи вынуждены были заимствовать термины из психологии (такие как мотивация, память, внимание и др.) в попытке объяснить увиденные закономерности. Учитывая то, что психологические понятия использовались лишь как средство обобщить наблюдавшиеся корреляционные закономерности, в подобных работах всегда присутствует некоторая «притянутость» заимствованной психологической терминологии. Психологу при знакомстве с такими физиологическими работами может показаться, что богатые и многогранные понятия его науки упрощены и искажены. Заметим, что альтернативой использованию психологической терминологии стало бы придумывание новых понятий (параллельных психологическим), что, строго говоря, было бы корректнее, но в конечном счете внесло бы еще больше путаницы.

И, конечно же, многим хотелось чего-то большего... Примитивные аспекты зрительного восприятия и примитивные аспекты управления движениями - это еще не психика, а лишь чуланчик, хозяйственная пристройка при ней. Разумеется, хотелось разгадать природу наиболее высших и сложных психических функций - мышления, сознания, причем идти не от корреляционных закономерностей, выявленных в эксперименте, а от теории.

И вот появились сначала «гностические нейроны», метко названные «нейронами моей бабушки» («grandmother cells»), потом «нейроны сознания». Впрочем, здесь нужно оговориться, что авторы подобных теорий далеко не всегда собирались помещать все человеческое сознание в один нейрон. Так, идея «нейронных коррелятов сознания» Ф. Крика и K. Koxa (Crick, 1994; Crick, Koch, 2002), известных как «нейроны сознания», хотя и связывает сознание с весьма небольшим количеством нейронов, но все же не претендует на то, что, зарегистрировав один нейрон, можно заглянуть в душу человека. Ф. Крик и К. Кох подчеркивают, что для полноценного сознания необходим весь мозг человека; иными словами, опыт сознания - это эмерджентное свойство мозга как целого. Однако, поскольку физиолог всегда вынужден идти от физиологического эксперимента, понятие сознания оказывается в такой работе редуцированным до весьма узких аспектов сенсорного восприятия. Тем не менее Ф. Крик и К. Кох констатируют, что выявление небольшого количества нейронов мозга, активность которых коррелирует с тем или иным сознательным восприятием, - лишь самый первый, начальный, хотя и очень важный шаг на пути к пониманию сознания, а большая часть работы еще впереди. Интересные размышления по поводу возможности нейрофизиологического изучения сознания, в частности, правомочности 
выделения «нейронов сознания», а также имевшихся в науке попыток описать сознание в терминах квантовой физики, изложены в работах Е.Н. Соколова (Соколов, 2007).

Непонимание между психологами и физиологами при оценке подобных физиологических работ может иметь как минимум две причины. Во-первых, в работах, подобной рассмотренной выше работе Ф. Крика и К. Коха, как правило, имеется в виду, что авторы понимают редукционистскую суть своих исследований (неизбежную и даже обязательную для физиологии!), но надеются перейти от редукционистской модели к полноценной когда-нибудь в будущем. А далее случается так, что громкий лозунг слышен всем, а оговорки же остаются незамеченными (нередко тому способствуют усилия журналистов, а такжедействия самих авторов, стремящихся к популяризации своих работ и поиску источников финансирования). И если подобная «игра» может быть понятна одному физиологу, читающему работу другого физиолога (при условии, что она не переходит границ дозволенного!), то психолог, видя подобные заявления, должен делать скидку на данное обстоятельство и постоянно держать в уме, где описана реальная работа, а где - планы и обещания на перспективу.

Вторая причина непонимания между психологами и физиологами отчасти связана с первой и также является следствием различия методологий двух наук. Выше мы уже упоминали, что психологические термины, попав в физиологию, преобразуются вследствие притирки к физиологической методологии. Но источник разногласий и непонимания не только в этом. Очень много путаницы в оценку терминов вносит многозначность ряда слов, в числе которых слово «сознание» является одним из лидеров. Для психолога слово «сознание» обычно подразумевает анализ его содержания и легко ассоциируется со словом «поток»; иными словами, говоря о сознании, психолог вслед за У. Джеймсом будет иметь в виду содержание этого сознания и изменение этого содержания во времени. Однако представьте себе врача, работающего с тяжелоранеными: для него есть всего два состояния сознания: либо больной в сознании, либо он без сознания (с некоторым спектром переходов между двумя состояниями). Если же углубиться в рассмотрение переходных уровней между этими крайними состояниями (большинство из которых, не считая сна, относятся к патологии), то можно вслед за С. Лорисом увидеть, что сознание для исследователя с медицинским или физиологическим мышлением разделяется на две независимые составляющие: уровень самоосознания и уровень бодрствования (The boundaries..., 2006). Каждая из этих составляющих в отдельности образует некоторый континуум, а вместе они составляют некоторое подобие квадрата на двумерной координатной плоскости. Нормальное деятельное состояния здорового человека и состояние комы окажутся в диаметрально противоположных углах квадрата, где оба показателя либо близки к нулю (кома), либо близки к максимуму (нормальное бодрствующее состояние). На плоскости квадрата оказываются также разбросаны различные 
другие состояния, включая как сновидения у здорового человека, так и хроническое вегетативное состояние, иногда наступающее при тяжелейшем поражении ассоциативных зон коры головного мозга.

Теперь обратите внимание: постановка вопроса о сознании в таком контексте допускает объективное физиологическое изучение сознания, в том числе с регистрацией активности отдельных нейронов, энцефалограммы, применения томографических методов визуализации мозга. Дело в том, что указанные составляющие сознания можно и нужно оценивать с помощью формализуемых объективных критериев, реализуемых в эксперименте. Далее в духе современной экспериментальной науки (в традициях позитивизма) можно анализировать корреляции между этими значениями и активностью мозга и на основе таких корреляций делать вывод, что такая-то область мозга или такие-то нейроны участвуют в такой-то функции. В принципе это все. Цели и средства их достижения должны соответствовать друг другу.

А что делать, если хочется прочитать мысли, узнать содержание сознания человека и сделать это, по возможности, объективными физиологическими методами? Судя по художественной и научно-популярной литературе, а особенно по тем вопросам, которые задают на лекциях студенты и неспециалисты в области физиологии, имеется большой общественный спрос на такие исследования. А вот тут-то и начинаются существенные трудности. Австралийский философ Д. Чалмерс весьма точно уловил суть так называемой психо- физиологической проблемы (оставим в стороне его пананимистические идеи и гипотезу «философского зомби»). Согласно мнению Д. Чалмерса, перед исследователями в области когнитивной науки, желающими изучить сознание, стоят два класса проблем: «легкие» и «трудные» (Chalmers, 1996). «Легкие» проблемы связаны с такими вопросами: как человек различает сенсорные воздействия и реагирует на них? как мозг интегрирует множество видов информации? как эта информация используется для управления поведением? как человек сообщает о том, что достигает его сознания? Нельзя, конечно, сказать, что эти проблемы легки на самом деле, но весь реальный прогресс нейрофизиологии и психофизиологии (включая упоминавшиеся выше работы С. Куффлера, Д. Хьюбела, Т. Визеля, Э. Эвартса и др.) шел именно в таком направлении. И именно так будет развиваться наука и дальше. Именно здесь психология и физиология способны помочь друг другу, обогатить друг друга, подсказать друг другу и совместно решать общие проблемы. «Трудная» проблема по сути одна: как физические процессы в мозге приводят к возникновению субъективных сознательных переживаний в психике (qualia)? Именно здесь и ломаются все копья по большому счету.

Удастся ли нам когда-нибудь решить «трудную проблему» (ведь, по сути, это переформулировка или уточнение все той же старой психофизиологической проблемы)? Если мы сейчас не видим решения задачи, то это не доказывает принципиальной невозможности ее решить. Может 
быть, когда-нибудь технологический прогресс даст нам нужные методы, ведь он уже дал физиологии очень много за последний век. Нобелевский лауреат Ф. Крик еще в 1990-е гг. заявил, что нейрофизиология уже обладает инструментами, чтобы пуститься в поиск того, как мозг рождает сознательные переживания человека (Crick, 1994). Очень большие надежды связывают сейчас с такими современными методами, как функциональная магнитно-резонансная томография и магнитоэнцефалография.

Впрочем, скорее всего, с развитием технологий мы будем успешно и все дальше продвигаться лишь в направлении решения «легких» проблем, например, создадим методы непосредственной передачи информации в мозг, минуя сенсорные органы, или усовершенствуем методы биоуправления до такой степени, что будем легко набирать текст на компьютере, не дотрагиваясь до клавиатуры. Но, вероятнее всего, техника никогда не даст нам возможности заглянуть в субъективное. Нетрудно представить себе, что когда-нибудь технологический прогресс предоставит нам возможность переписать личность человека в компьютер путем сканирования всего мозга человека нейрон за нейроном, синапс за синапсом. Тогда теоретически мы обретем виртуальное бессмертие и будем внутри компьютерного процессора жить, радоваться и огорчаться (фантасты уже давно обыгрывают такую возможность). Но при этом мы ни на миллиметр не продвинемся в решении «трудной» проблемы, в разгадке субъективного: как, каким образом, по каким зако- нам эта суперсложная компьютерная программа будет иметь свое сознание. Исследовать такую программу будет совсем не проще, чем исследовать живой мозг человека. Более того, наблюдая со стороны, мы даже не сможем достоверно убедиться, действительно ли такая компьютерная программа воспроизведет субъективный внутренний мир человека или же будет лишь воссоздавать его внешние проявления по типу «философских зомби» Д. Чалмерса (Chalmers, 1996). Принципиальную невозможность заглянуть в субъективное даже таким экстравагантным способом, как компьютерная модель психики человека, косвенно демонстрирует «тест Тьюринга» (Turing, 1950) и особенно мысленный эксперимент «китайская комната», предложенный Д. Сирлом (Searle, 1990).

Вероятнее всего, нам никогда не будет дано заглянуть в субъективное физиологическими методами. Видимо, в этом состоит некое фундаментальное свойство данного явления. Это, однако, не означает, что нужно запрещать науке пытаться выяснить, на основе каких нервных процессов рождается субъективное, какие поражения мозга в результате травмы лишают человека этого субъективного. Подчеркиваем, речь идет о выяснении физиологической подоплеки психических явлений, но никак не о надежде заглянуть в субъективное через нейроны, мозговые волны и пр.

Две науки - два подхода к исследованию самого сложного в известной нам вселенной - человеческой психики и человеческого мозга. Наверное, психолог и физиолог смогут понять друг друга, если уяснят для себя, чем эти две науки отличаются 
друг от друга. Хочется верить, что совместная работа и тесный контакт между представителями двух наук психологии и физиологии - помогут построить основу нового знания, в котором ставятся важные, интересные и, главное, принципиально решаемые проблемы. Все это как раз те проблемы, которые Д. Чалмерс назвал «легкими». А проблему чтения мыслей по излучению от нейрона оставим

\section{Литература}

Бернштейн Н.А. Очерки по физиологии движений и физиологии активности. М.: Медицина, 1966.

Бернштейн Н.А. Физиология движений и активность. М.: Наука, 1990.

Василюк Ф.Е. Методологический анализ в психологии. М.: Смысл; МГППУ, 2003.

Декарт Р. Размышления о первой философии // Декарт Р. Соч. В 2 т. М.: Мысль, 1994. Т. 2. С. 16-72.

Зинченко В.П. Ответ психолога физиологам («Работа по психологии» Г.Г. Шпета) // Вопросы психологии. 2009. № 3. C. $72-82$.

Мазилов В.A. Методологические проблемы психологии в начале XXI века // Психологический журнал. 2006. № 1. C. 23-34.

Павлов И.П. Ответ физиолога психологам // Павлов И.П. Полн. собр. соч. В 6 т. М.;Л., 1951. Т. 3. Кн. 2.

Павлов И.П. Физиология больших полушарий головного мозга. М.: Книжный дом «ЛИБРОКОМ», 2010.

Сеченов И.М. Рефлексы головного мозга. М.: Изд-во АН СССР, 1961.

Соколов Е.Н. Очерки по психофизиологии сознания // Вестн. Моск. ун-та. Сер. 14. Психология. 2007. № 4. С. 11-19. научной фантастике. И субъективное будем изучать адекватными для этого методами. А закончить хочется напоминанием хорошо известного и очень оптимистического высказывания К.Г. Юнга: «Вероятно, придет день, когда биолог, и не только он, но и физиолог протянут руку психологу и встретятся с ним в туннеле, который они взялись копать с разных сторон горы неизвестного» (Юнг, 1995).

Ухтомский А.А. Избр. труды. Л., 1978.

Шеррингтон Ч. Интегративная деятельность нервной системы. Л.: Наука, 1969.

Юнг К.Г. Конфликты детской души. М.: Канон, 1995.

Brown T.G. The intrinsic factors in the act progression in mammal // Proc. R. Soc. Lond. 1911. 84. 308-319.

Chalmers $D_{i} J$. The Conscious Mind: In Search of a Fundamental Theory. N.Y.: Oxford University Press, 1996.

Crick F. The Astonishing hypothesis: The scientific search for the soul. N.Y: Scribner, 1994.

Crick F., Koch C. The problem of consciousness // Scientific American. Special Edition. 2002. 12. 1. 11-17.

Searle J.R. Is the Brain's mind a computer program? // Scientific American. 1990. 262. 26-31.

Sperry R.W. Hemisphere deconnection and unity in consciousness // American Psychologist. 1968. 23. 723-733.

The boundaries of consciousness: Neurobiology and neuropatholog / S. Laureys (ed.). Amsterdam: Elsevier, 2006.

Turing $A$. Computing machinery and Intelligence // The Mind. 1950. 59. 433-460. 